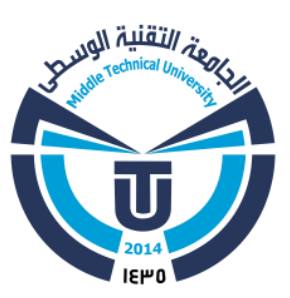

\title{
JOURNAL OF TECHNIQUES
}

Journal homepage: http://journal.mtu.edu.iq

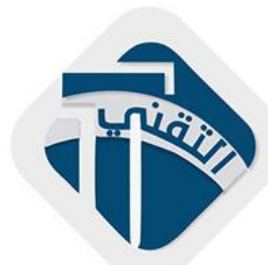

مقاله بحثيه ـ التقنيات الادارية

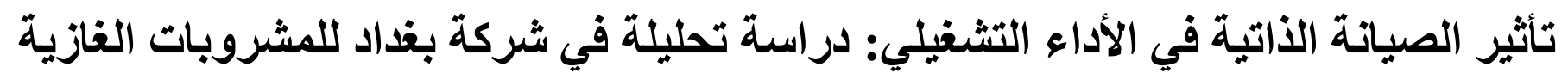

عامر عبد اللطيف كاظم العامري1 *، سالم بلر محمد²، عمر عامر حامد الراشد1

1 الكلية التقنية الادارية / بغداد

2 المعهد التقني / الأنبار

ameralamery313@gmail.com البريد الإلكتروني: مطات

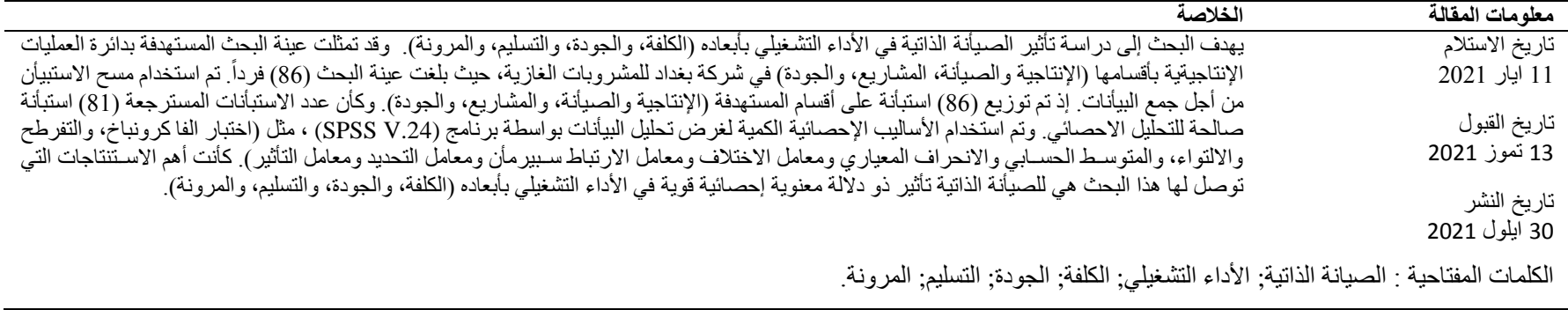

The Impact Autonomous Maintenance on Operational Performance: An Analytical Study at the Baghdad Soft Drinks

\section{Company}

Amer Abdul Latif Kadhum Al-Amery ${ }^{*}$, Salem Bader Mohammad², Omar Amer Hamed Al-Rashed ${ }^{1}$

${ }^{1}$ Technical College of Management - Baghdad, Middle Technical University, Baghdad, Iraq.

${ }^{2}$ Technical Institute / Anbar, Middle Technical University, Baghdad, Iraq.

* Corresponding author E-mail: ameralamery313@gmail.com

\begin{tabular}{|c|c|}
\hline Article information & Abstract \\
\hline Article history: & $\begin{array}{l}\text { This research aims to investigate the impact of autonomous maintenance on operational performance dimensions that focuses on } \\
\text { cost, quality, delivery, and flexibility. The research sample has targeted the departments of production operations namely; }\end{array}$ \\
\hline & production, maintenance, projects, and quality in the Baghdad Company for Soft Drinks. Data collected by using a survey \\
\hline Received & questionnaire. In total (86) staff were invited to practice in this survey. There are (81) forms that were valid for statistical analysis. \\
\hline 11 May 2021 & $\begin{array}{l}\text { Quantitative statistical methods were used for the purpose of data analysis using the (SPSS V.24) program such as; Cronbach's } \\
\text { alpha test, kurtosis and skewness, arithmetic mean, standard deviation, coefficient of variation. Spearman's correlation }\end{array}$ \\
\hline $\begin{array}{l}\text { Accepted } \\
13 \text { July } 2021\end{array}$ & $\begin{array}{l}\text { coefficient, coefficient of determination and impact factor. conclusions, the most important conclusions reached by this research } \\
\text { are that autonomous maintenance has a strong statistically significant effect on the dimensions of operational performance, } \\
\text { especially cost, quality, delivery, and flexibility. }\end{array}$ \\
\hline
\end{tabular}

30 September 2021

Keywords: Autonomous Maintenance; Operational Performance; Cost; Quality; Delivery; Flexibility. 


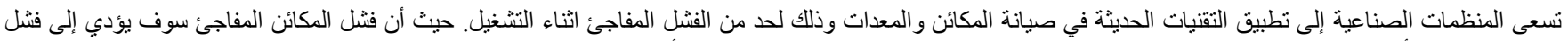

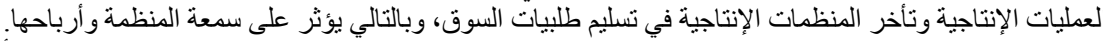

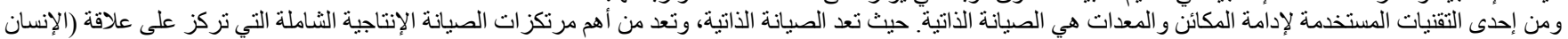

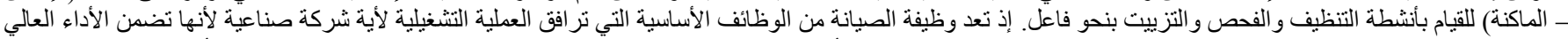

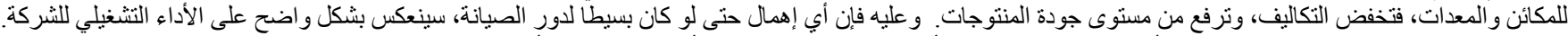

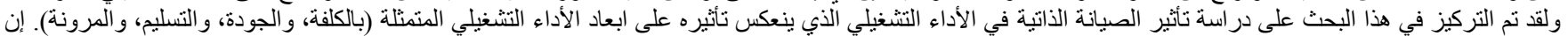

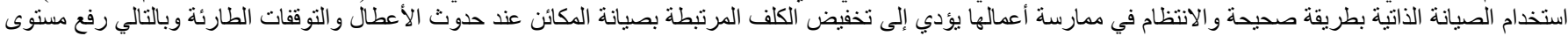

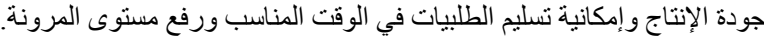

2

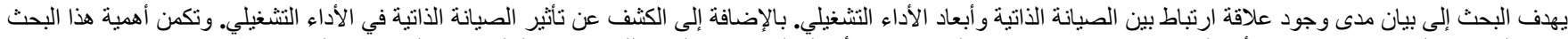

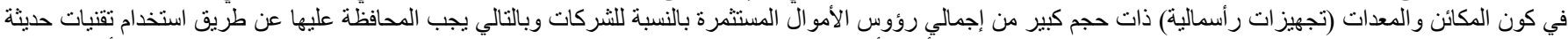

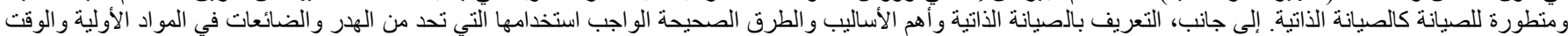

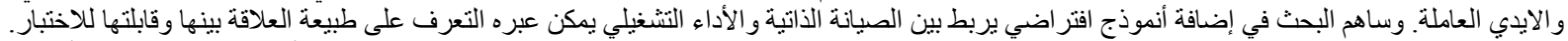

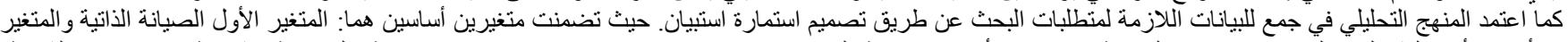

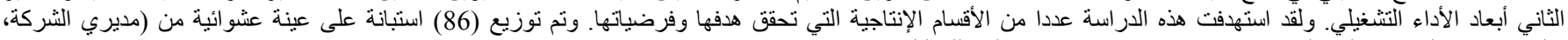

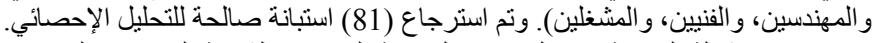

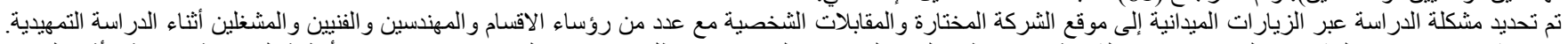

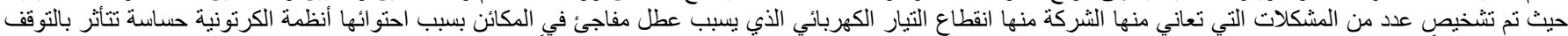

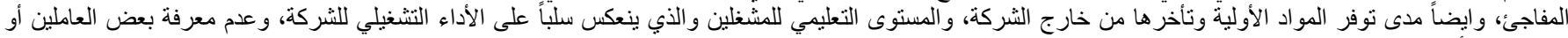

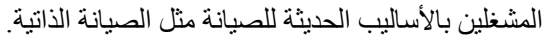

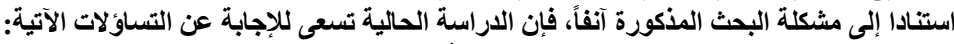

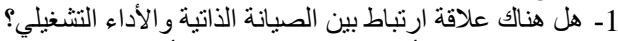

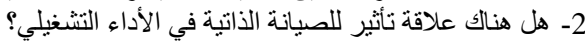

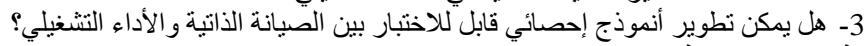

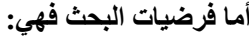

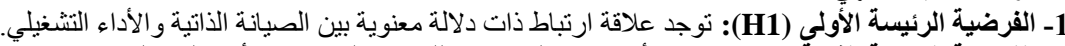

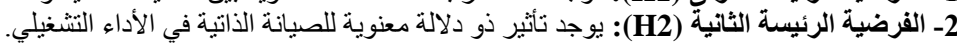

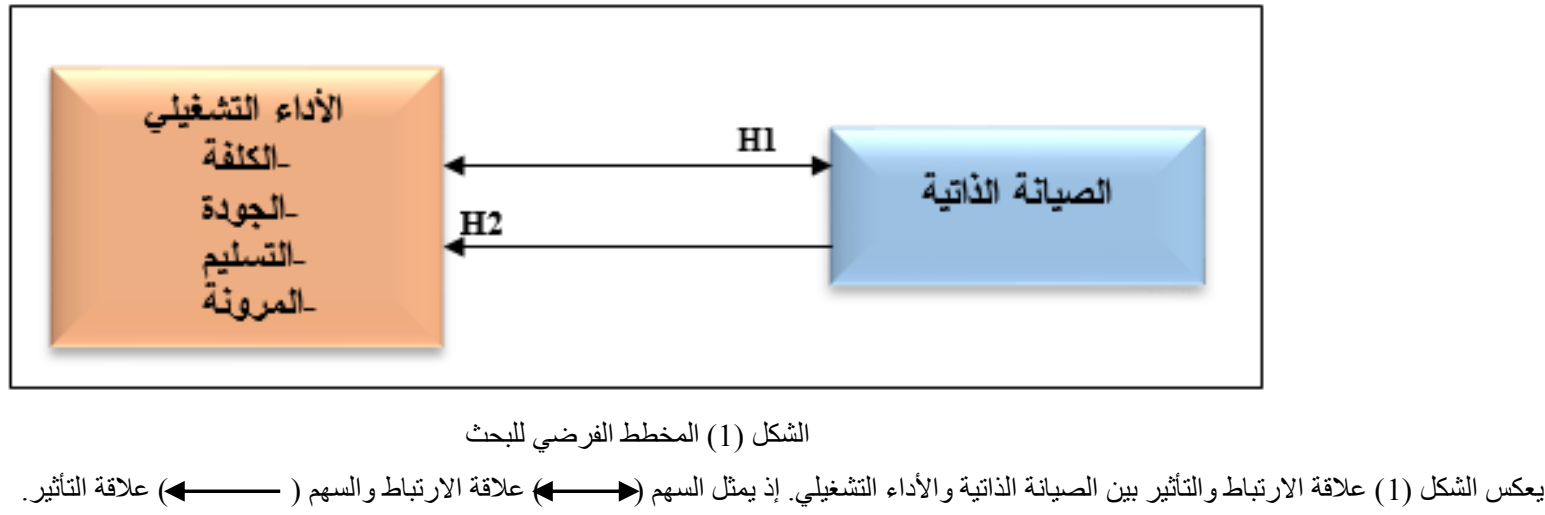

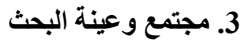

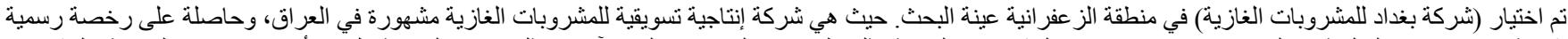

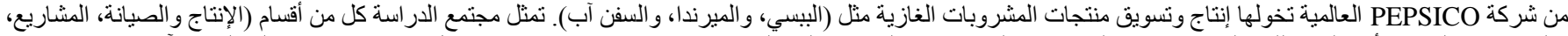

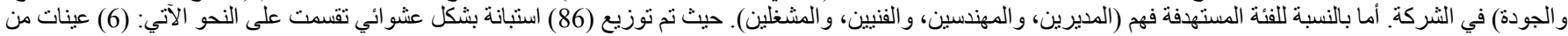

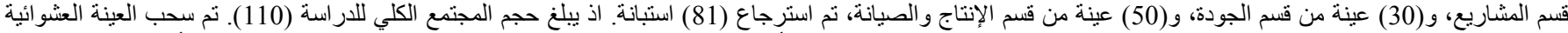

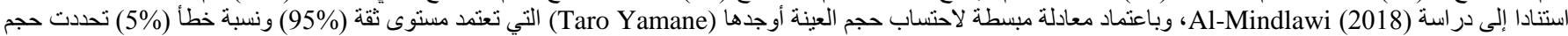
العينة المسحوبة بـ (86) وكما يأتي:

$$
\begin{aligned}
& \mathbf{n}=\frac{N}{\mathbf{1}+N(e)^{2}} \\
& \mathbf{n}=\frac{110}{1+110(0.05)^{2}} \\
& \mathbf{n}=\mathbf{8 6} \\
& \text { إذ أن:n = حجم العينة، N = حجم المجتمع، e = احتمال الخطأ (5\%) عند مستوى الثقة (95\%). }
\end{aligned}
$$


Amer A. K. et.al, Journal of Techniques, Vol. 3, No. 3, September 30, 2021, Pages 57-67

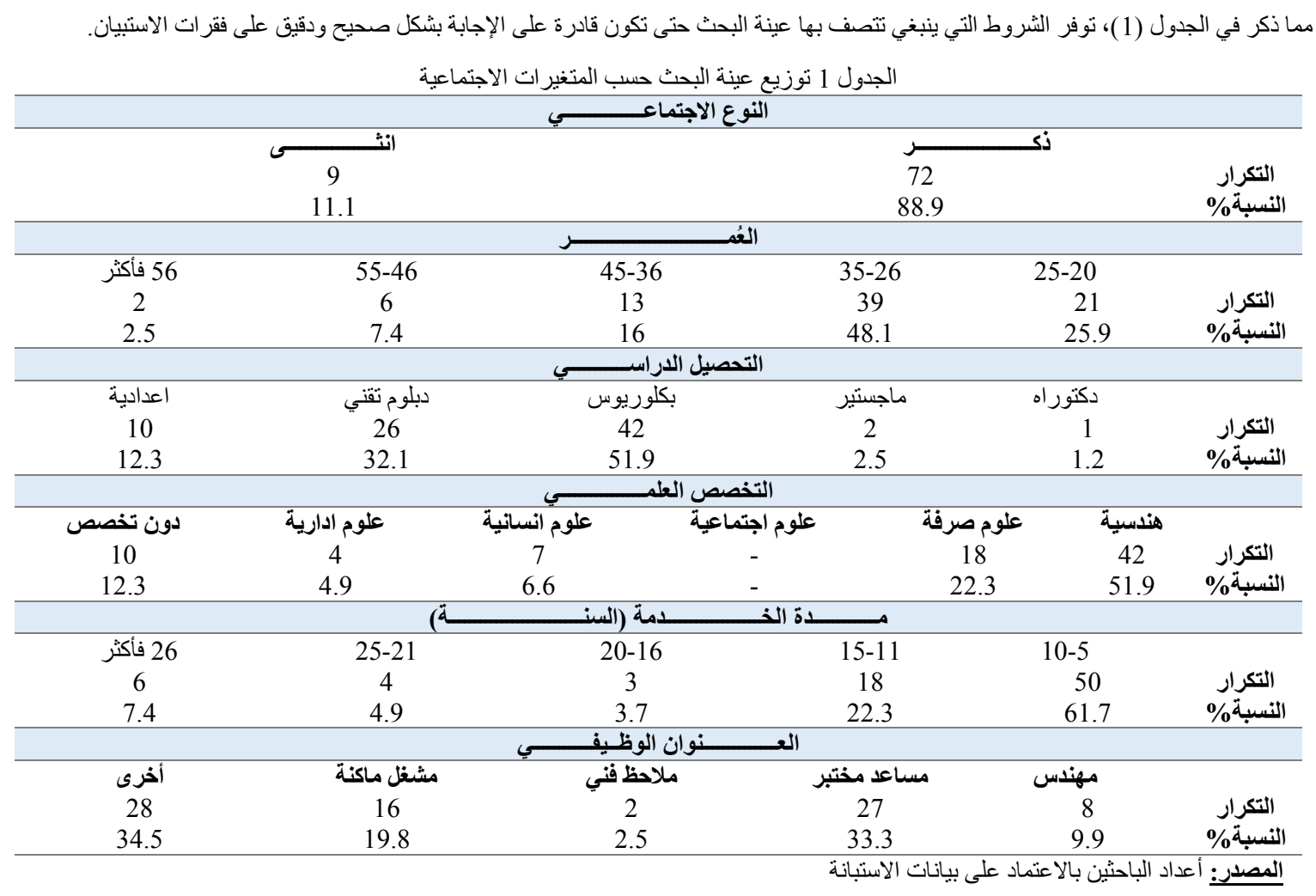

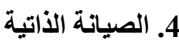

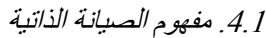

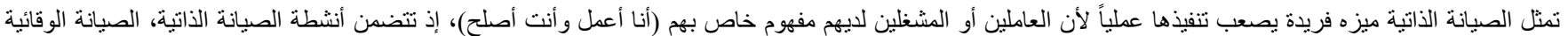

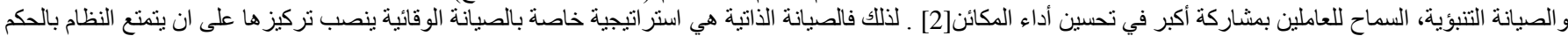

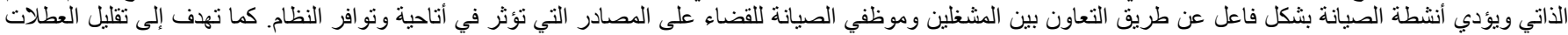

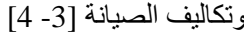

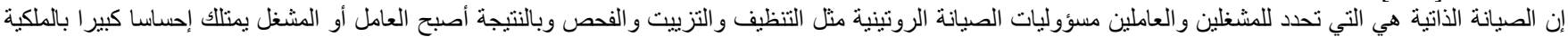

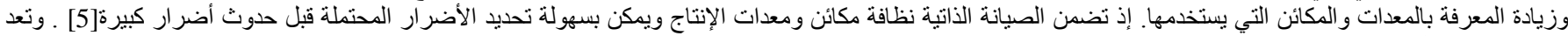

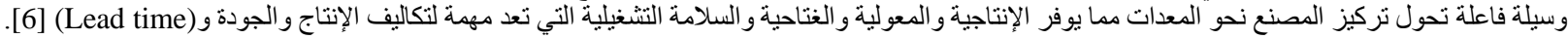
4.1

تتكون الصبانة الذاتية من سبع خطو ات [8 - 7 - 7 - 6]:

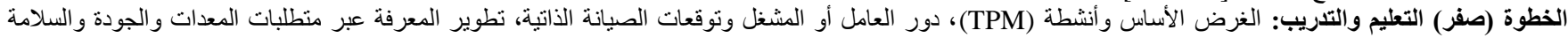

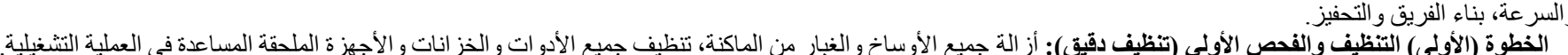

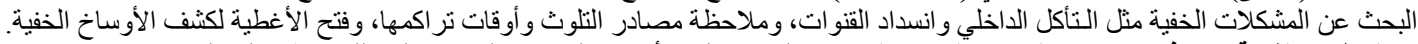

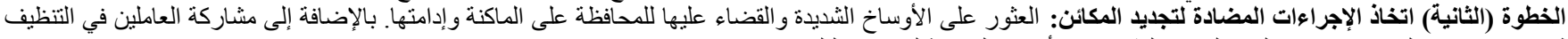

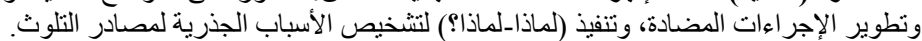

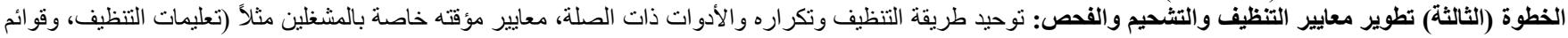

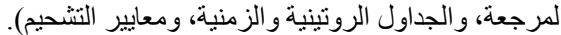

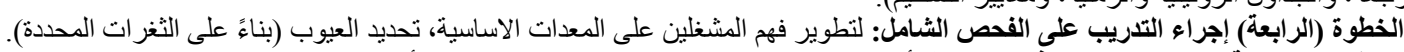

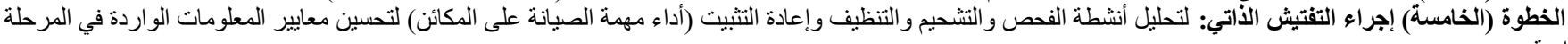

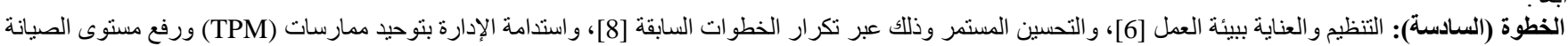

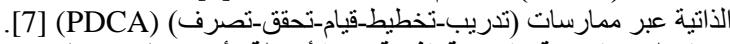

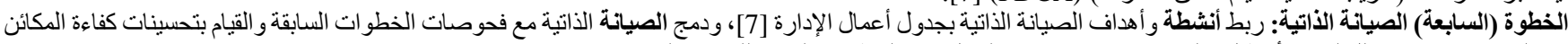

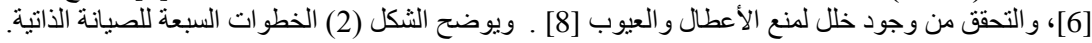




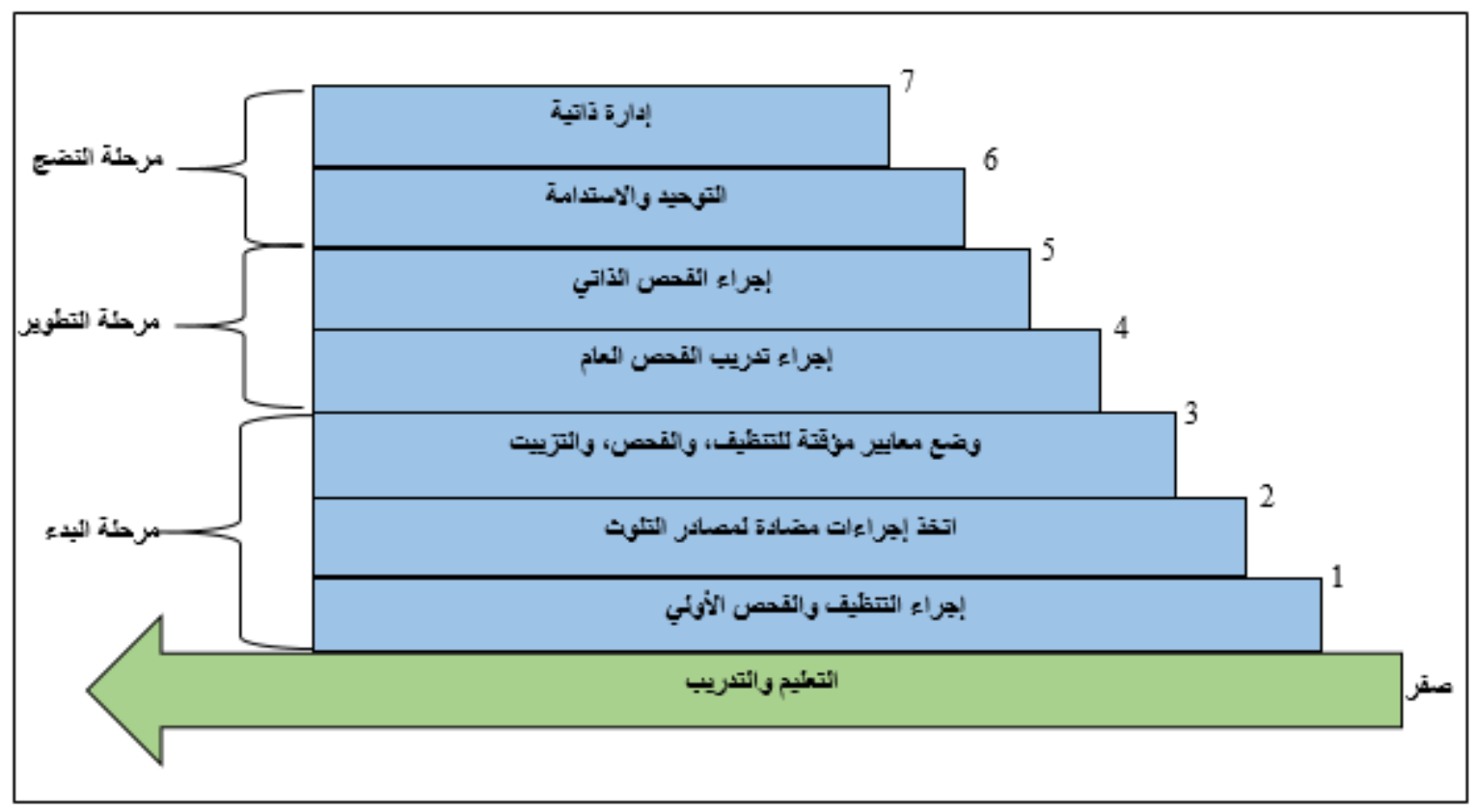

الثكل (2): الخطو ات السبعة للصيانة الذاتية

Source: Agustiady, Tina Kanti \& Cudney, Elizabeth A. (2016), Total Productive Maintenance: Strategies and Implementation Guide, $1^{\text {st }}$ ed., p: 152.

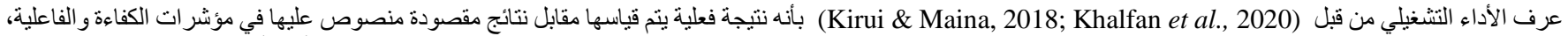

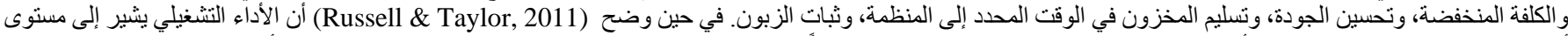

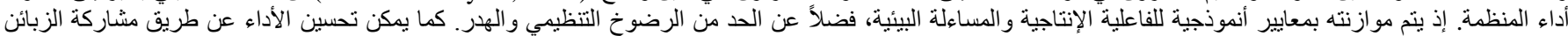

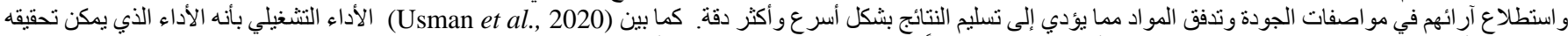

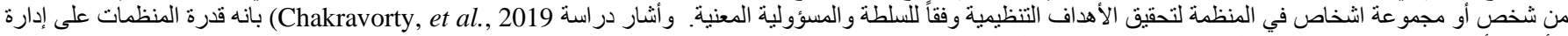

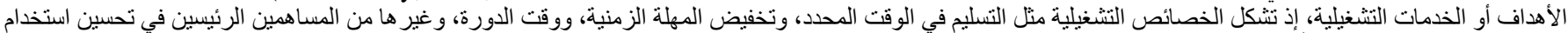

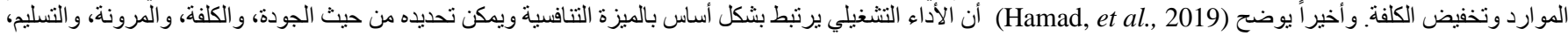
والابداع.

5.1 أبعاد الأداء التشغيلي

في هذا البحث تم اعتماد ابعاد الأداء التشغيلي الآتية (الكلفة، و الجودة، و التسليم، و المرونة) من أجل بيان مدى تأثر ها بالصيانة الذاتية.

2.1.1

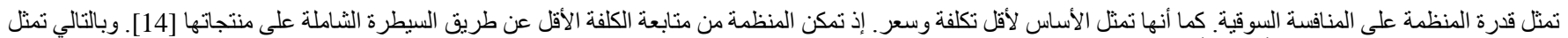

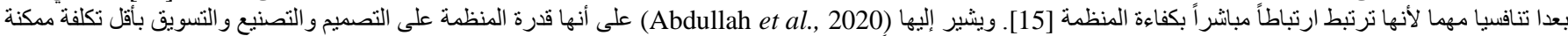

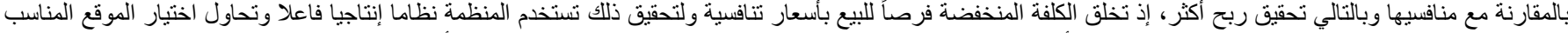

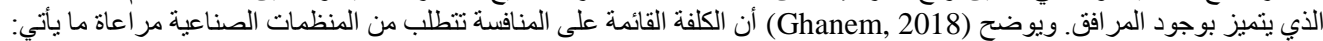
استخدام الأصول الثابتة والكتداولة بشكل اقتصادي.

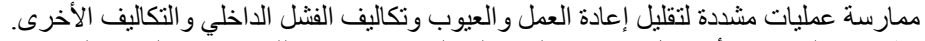

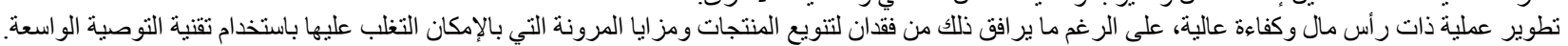
الحفاظ على أدنى حد من مستويات المخزون، مع ضمان ضمان استمر ار عمليات الإنتاج.

5.1.2

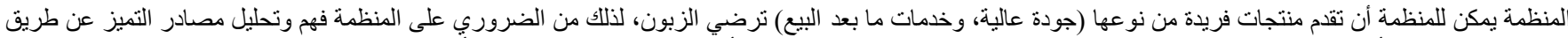

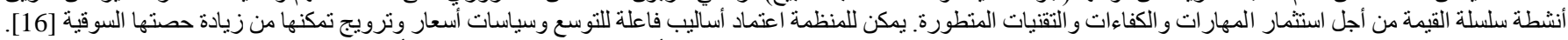

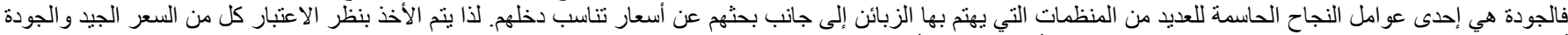

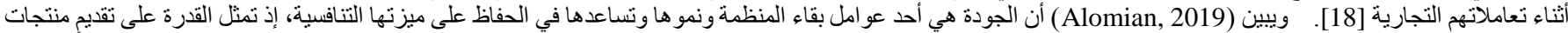

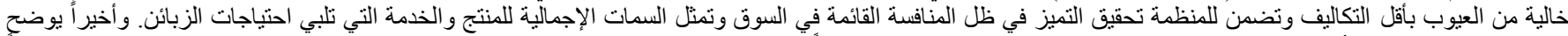

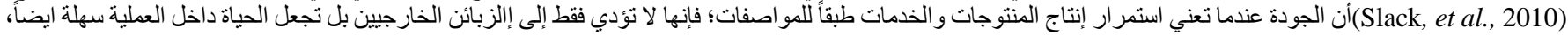
فالجو دة داخل العملية تهدف إلىى:

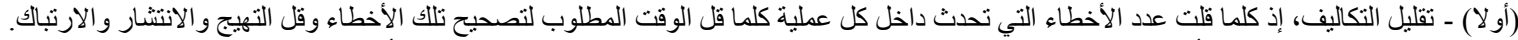

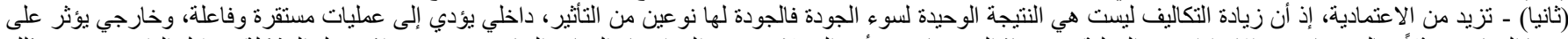

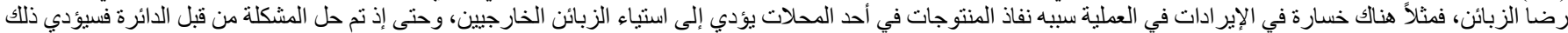




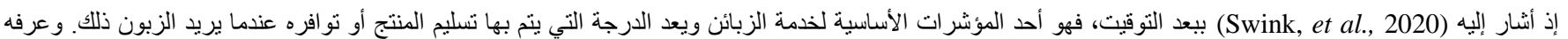
(Sachitra, 2017)

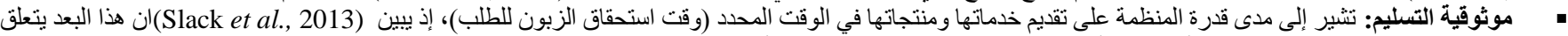

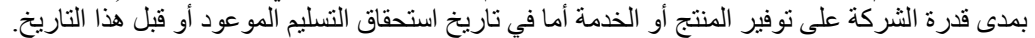

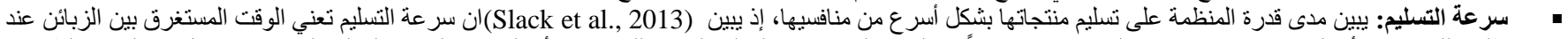

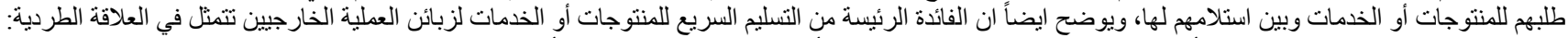

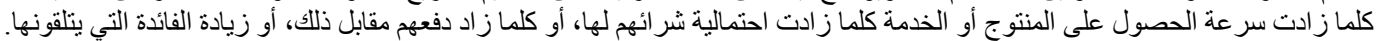

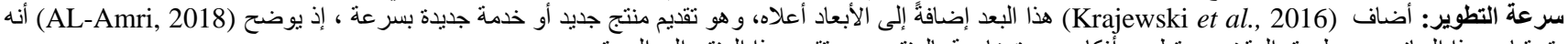

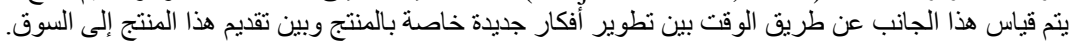

5.1.4 المرونة

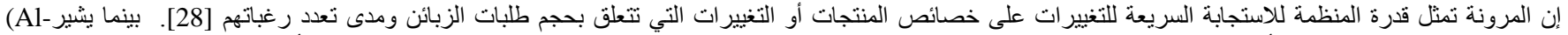

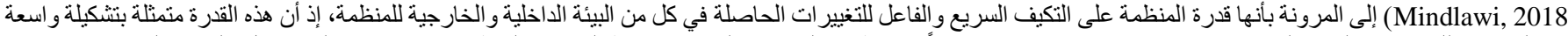

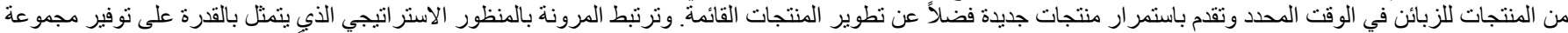

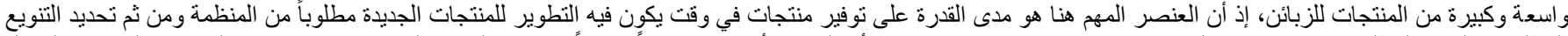

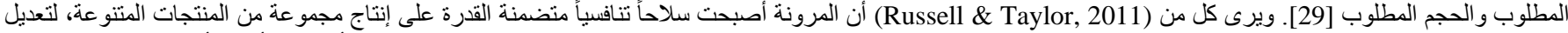

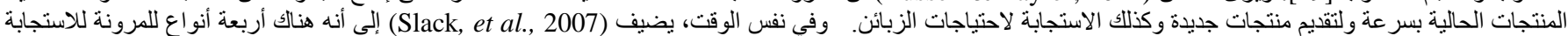
اللتغير ات الحاصلة في طلبات الزبائن: • مرونة المنتوج والخدمة: و هي مدى قانق قدرة العملية التشغيلية على إدخال منتوجات أو خدمات معدلة أو جديدة، أب القدرة على إجر اء تغيير ات في التصميم أو إطلاق منتجات جديدة

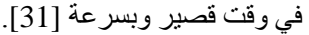

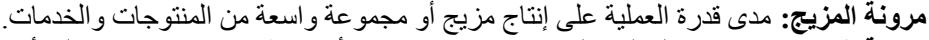

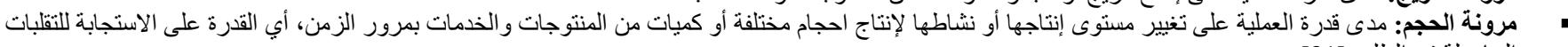

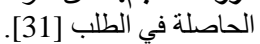
" مرونة التسليم: مدى قدرة العطلية على تغيير تقديم أو توقيت منتوجاتها وخدماتها.

6. تحليل البيانات ومناقشة النتائج 6.1 - - اختبار/ت الصدق والثبات يوضح الجدول (2) اختبار ات الصدق و الثبات لهذا البحث الجدول 2 معامل الفاكرونباخ لثبات وصدق مقياس الاستبانة

\begin{tabular}{|c|c|c|c|}
\hline الفقرات & معامل الثبات & Aقيمة الفا كرونباخ & المتغيرات \\
\hline 6 & 0.829 & 0.688 & الصيانة الذاتية \\
\hline 6 & 0.885 & 0.783 & الكلفة \\
\hline 6 & 0.832 & 0.693 & الجودة \\
\hline 6 & 0.924 & 0.854 & التسليم \\
\hline 6 & 0.877 & 0.799 & المرونة \\
\hline 24 & 0.953 & 0.909 & الأداء التشغيلي \\
\hline 30 & 0.904 & 0.818 & الإجمالي \\
\hline
\end{tabular}

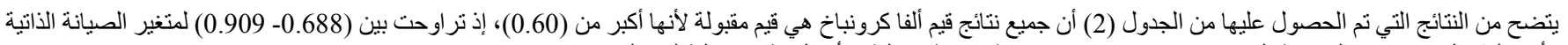

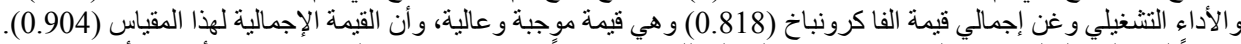

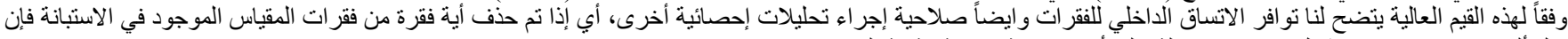

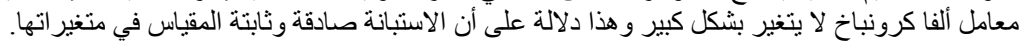

6.2. اختبار التوزيع الطبيعي باستخدامقيم الالتواء (Skewness) والتفرطح (Kurtosis)

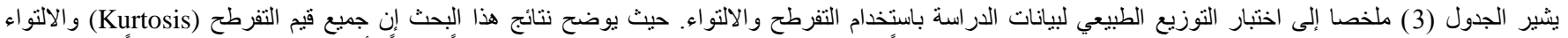

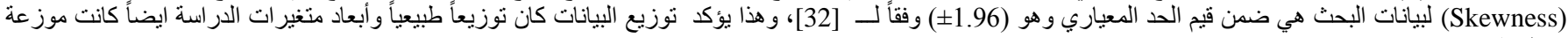

الجدول 3 اختبار التوزيع الطبيعي لبيانات الدر اسة باستخدام التفرطح و الالتو اء الأواء التواء

\begin{tabular}{|c|c|c|c|}
\hline Skewness الإلتواء & Kurtosis التفرطح & الأبعاد & متغيرات الاراسة \\
\hline-0.300 & -0.519 & الصيانة الذاتية & المتغير المستقل \\
\hline-0.443 & -0.335 & الكلفة & \multirow{4}{*}{ الأداء التتشغيلي التابع } \\
\hline-1.446 & 1.233 & 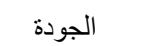 & \\
\hline-0.427 & -0.279 & 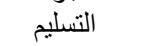 & \\
\hline-0.220 & -0.495 & 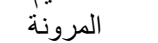 & \\
\hline \multicolumn{4}{|c|}{ SPSS-V.24 المصدر : إعداد الباحثين باستخدام برنامج } \\
\hline
\end{tabular}


Amer A. K. et.al, Journal of Techniques, Vol. 3, No. 3, September 30, 2021, Pages 57-67

6.3. التحليل الوصفي الإحصائي لمتغبرات البحث

سوف ينم عرض تفسير نتائج لإجابات أفراد العينة حول متغير ات الدر اسة وأبعادها عبر إجر اء المقاييس الإحصائية من (المنوسط، الانحر اف المعياري ومعامل الاختلاف)، ويعرض

الجدول 4 فئات الأوساط الحسابـية

\begin{tabular}{|c|c|c|c|c|c|}
\hline $5-4.21$ & $4.20-3.41$ & $3.40-2.61$ & $2.60-1.81$ & $1.80-1$ & المتوسط \\
\hline أتفق تماماً & أتفق & أتفق إلى حد ما & لا أتفق & لا أتفق تماماً & القياس \\
\hline 5 & 4 & 3 & 2 & $=1$ & درجة المقياس \\
\hline عال جداً & عال & وسط & ضعيف & ضعيف جداً & مستوى الاهتمام \\
\hline
\end{tabular}

Source: Likert, R. (1932), Atechique for the Measurement of Attitudes, Archie's of psychology, New York: Columbia University press

يمكن عرض نتائج التحليل الوصفي الإحصائي لمتغير ات البحث الحالية عبر

6.3.1. تحليل إجابات عينة البحث للمتغير المستقل (الصيانة الذاتية)

إذ يوضح الجدول (5) التحليل الوصفي لإجابـــات أفر اد عينة الدراســــة عن المتغير المستــل (الصيانة الذاتية) وكالاتي

الجدول 5 تحليل إجابات أفر اد العينة عن بُعد الصيانة الذاتية

\begin{tabular}{|c|c|c|c|c|c|}
\hline 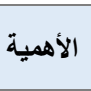 & الإختلاف معامل \% & 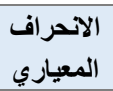 & 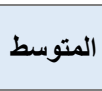 & 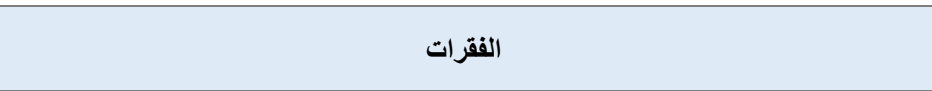 & ت \\
\hline 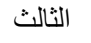 & 17.42 & 0.749 & 4.30 & يمارس العاملين بحرية كاملة المهمات البسيطة للصيانة كالتنظيف و التزييت و التشحيم. & 1 \\
\hline 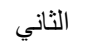 & 17.14 & 0.742 & 4.33 & توفر الثركة المستلزمات الأساسية لدعم الصيانة الذاتية. & 2 \\
\hline 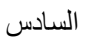 & 25.00 & 1.140 & 3.56 & تنظم الثركة دور ات تدريبة للعاملين لمو اكبة التطور ات المستمرة لمهمات الصيانة المختلفة. & 3 \\
\hline 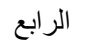 & 19.63 & 0.840 & 4.28 & تسعى الشركة لحث العاملين و المشغلين بإجر اء الفحوصات المستمرة لمكائنهم ومعداتهم. & 4 \\
\hline الأول & 16.02 & 0.681 & 4.25 & 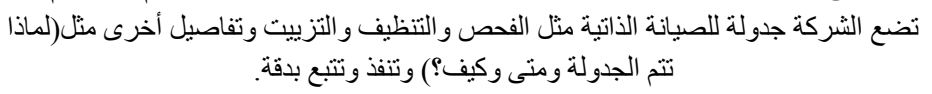 & 5 \\
\hline الخامس & 19.91 & 0.813 & 4.30 & تحدد الشركة مو اعيد لتنظيف الآلات و المعدات بشكل شامل من المشغلين وبمساعدة من قسم & 6 \\
\hline $\mathrm{n}=81$ & 19.84 & 0.828 & 4.17 & الصيانة الذاتية & $\mathbf{X}$ \\
\hline
\end{tabular}

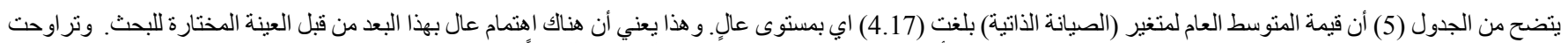

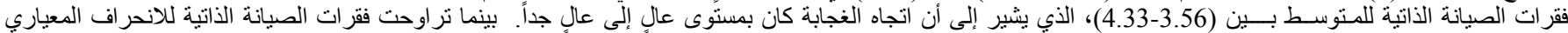

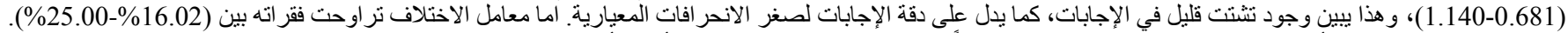

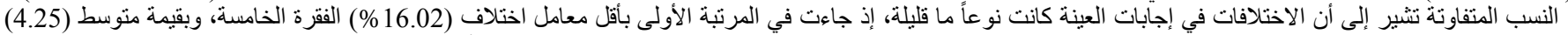

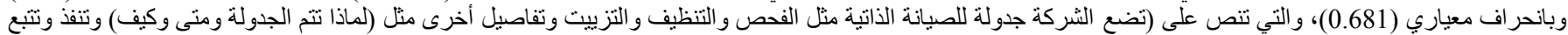

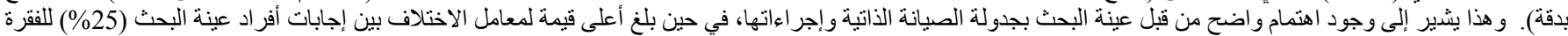

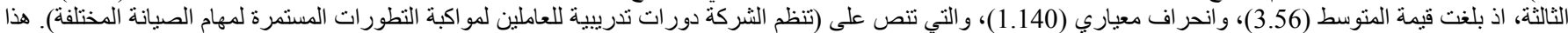

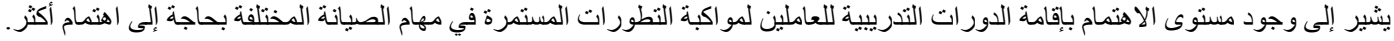
6.3.2. تحليل إجابات عينة البحث للمتغير التابع (الأداء التشغيلي)

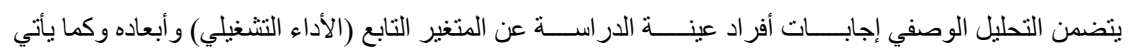
6.3.2.1. تحليل الكلفة

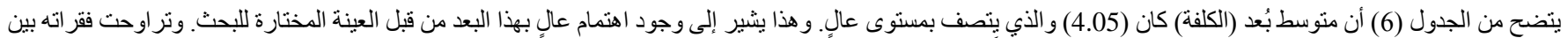

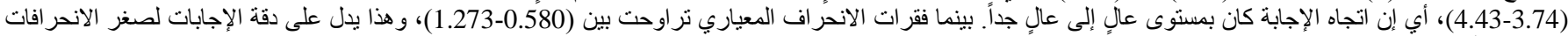

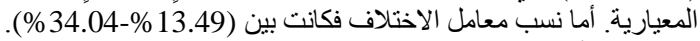

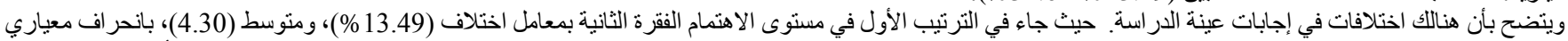

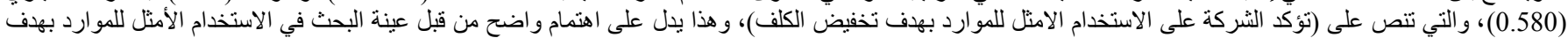

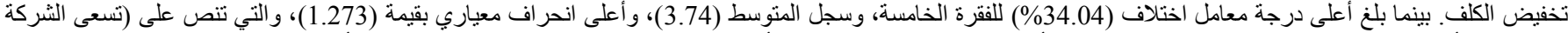
لاستخدام مبدأ إعادة التدوير لخفض الخف درجاليف)، وهذا يدل على أن مستوى الاهتمام باستخدام مبدأ إعادة التدوير لخفض التكاليف بحاجة إلى اهتمام أكثر.

الجدول 6 تحليل إجابات أفراد العينة عن الكلفة

\begin{tabular}{|c|c|c|c|c|c|}
\hline 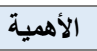 & معامل الإختلاف \% & الاتحر اف المعياري & 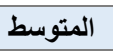 & 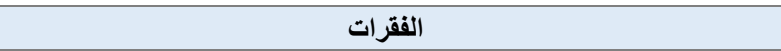 & $ت$ \\
\hline 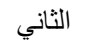 & 17.47 & 0.774 & 4.43 & تسعى الثركة إلى تقديم منتوجات أفضل للزبائن وبأسعار مناسبة. & 1 \\
\hline 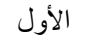 & 13.49 & 0.580 & 4.30 & تؤكد الشركة على الاستخدام الأمثل للمو ارد بهدف تخفيض الكلف. & 2 \\
\hline 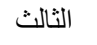 & 22.57 & 0.932 & 4.13 & تركز الشركة على نشاط البحث و التطوير لتخفيض التكاليف. & 3 \\
\hline 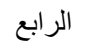 & 26.45 & 1.021 & 3.86 & تقدم الثركة أسعار أقل من أسعار المنافسين بحيث يمكن للزبائن مقارنة تأثيرها. & 4 \\
\hline 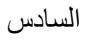 & 34.04 & 1.273 & 3.74 & تسعى الثركة لإستخدام مبدأ إعادة التدوير لخفض التكاليف. & 5 \\
\hline 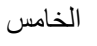 & 29.26 & 1.112 & 3.80 & تسعى الشركة لتقديم منتوجات بكلفة أقل من المنافسين. & 6 \\
\hline $\mathrm{n}=81$ & 23.43 & 0.949 & 4.05 & الكلفة & Y1 \\
\hline
\end{tabular}




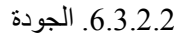

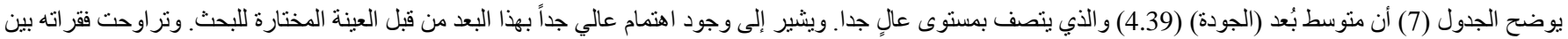

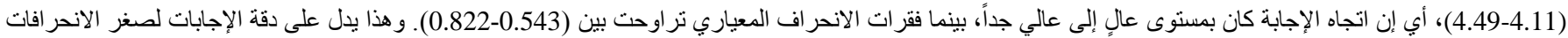

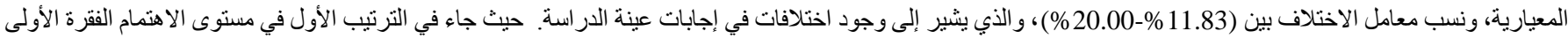

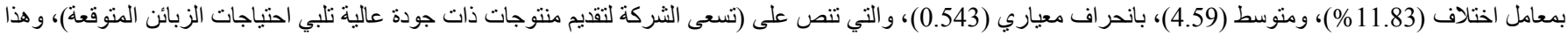

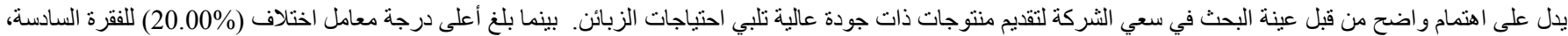

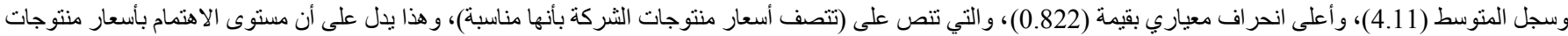

الجدول 7 تحليل إجابات أفر اد العينة عن متغير الجودة

\begin{tabular}{|c|c|c|c|c|c|}
\hline الأهمية & معامل & الالمعراف & 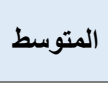 & 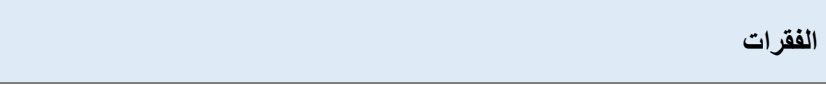 & $ت$ \\
\hline الأول & 11.83 & 0.543 & 4.59 & تسعى الثركة لتقديم منتوجات ذات جودة عالية تلبي احتياجات الزبائن المنوقعة. & 1 \\
\hline 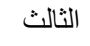 & 13.70 & 0.615 & 4.49 & تؤمن الشركة بتحقيق أهداف الجودة عن طريق تقليل الهدر و الضياعات في الإنتاج. & 2 \\
\hline الثناني & 13.30 & 0.593 & 4.46 & تستخدم الشركة الأساليب الإحصائية في السيطرة على الجودة. & 3 \\
\hline 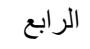 & 17.45 & 0.780 & 4.47 & تعتمد الشركة على فريق متخصص لضبط الجودة و السيطرة عليها. & 4 \\
\hline 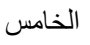 & 18.60 & 0.813 & 4.20 & تستلم الثركة تقارير جودة موثوقة من الزبائن يجري توصيلها إلى الإدارة المعنية. & 5 \\
\hline 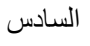 & 20.00 & 0.822 & 4.11 & تتصف أسعار منتوجات الثركة بأنها مناسبة. & 6 \\
\hline $\mathrm{n}=81$ & 15.81 & 0.694 & 4.39 & 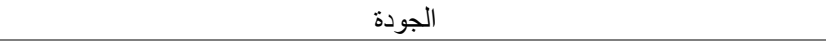 & Y2 \\
\hline
\end{tabular}

6.3.2.3 التسليم

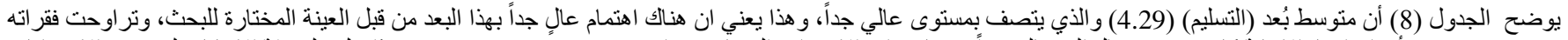

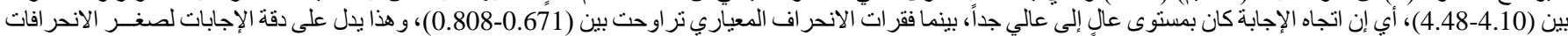

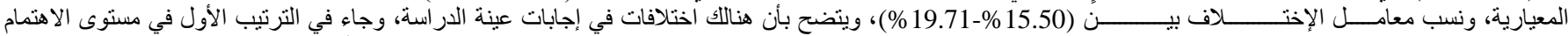

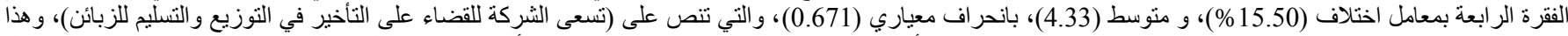

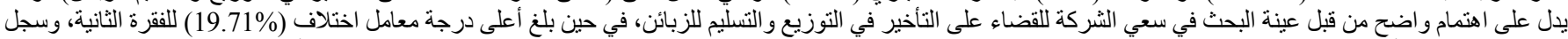

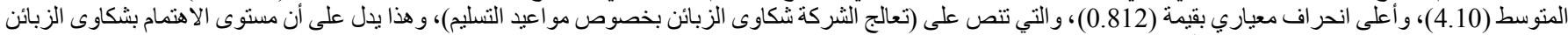
بخصوص مو اعيد التسليم بحاجة إلى أهنمأم أكثر.

\begin{tabular}{|c|c|c|c|c|c|}
\hline الأهمية & الإختلاف \% معل & الانحراف & المتوسط & 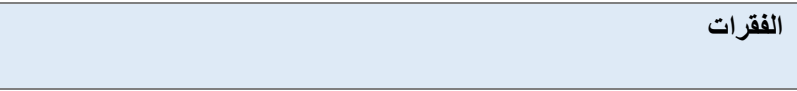 & $ت$ \\
\hline الرابع & 17.32 & 0.776 & 4.48 & تؤمن الثركة بمبدأ السرعة في تسليم المنتوجات لكسب رضا الزبائن. & 1 \\
\hline 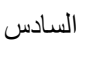 & 19.71 & 0.812 & 04.1 & تعالج الثركة شكأوى الزبائن بخصوص مو اعيد التسليم. & 2 \\
\hline 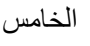 & 19.28 & 0.808 & 4.19 & تمتللك الثركة بر امج صيانة تمنع التوقفات إلى الحد الأدنى للوفاء بمو اعيد التسليم. & 3 \\
\hline 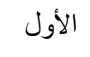 & 15.50 & 0.671 & 4.33 & تسعى الثركة للقضاء على التأخير في التوزيع و التسليم للزبائن. & 4 \\
\hline 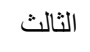 & 17.23 & 0.729 & 4.23 & تمنللك الثركة ارشادات (جدأول) زمنية محددة لتسليم المنتجات إلى الزبائن. & 5 \\
\hline 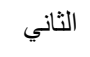 & 15.55 & 0.681 & 4.38 & تسعى الشركة لجعل دقة التسليم لديها أفضل من منافسيها. & 6 \\
\hline $\mathrm{n}=81$ & 17.39 & 0.746 & 4.29 & التسليم & Y3 \\
\hline
\end{tabular}

6.3.2.4 المرونة

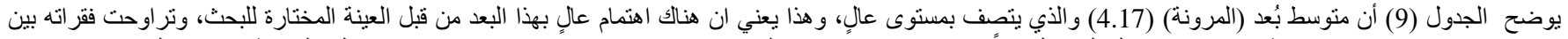

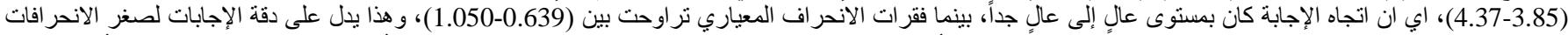

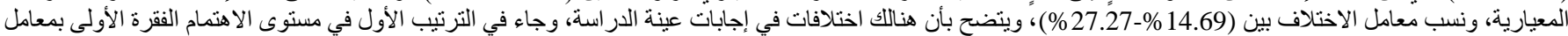

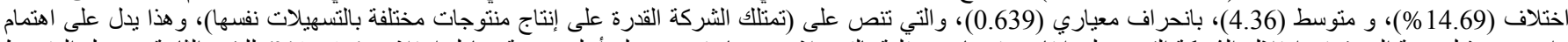

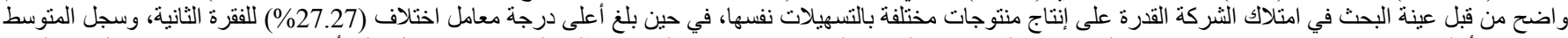

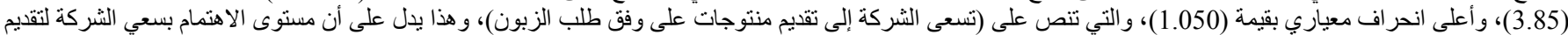

الجدول 9 تحليل إجابات أفر اد العينة عن متغير المرونة

\begin{tabular}{|c|c|c|c|c|c|}
\hline 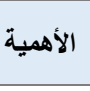 & الإختلاف معامل & المعياري & 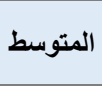 & 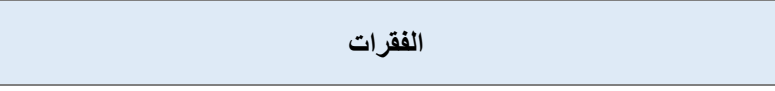 & $ت$ \\
\hline 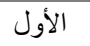 & 14.69 & 0.639 & 4.36 & تمتلك الثركة القدرة على إنتاج منتوجات مختلفة بالتسهيلات نفسها. & 1 \\
\hline 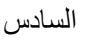 & 27.27 & 1.050 & 3.85 & تسعى الشركة إلى تقديم منتوجات على وفق طلب الزبون. & 2 \\
\hline 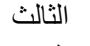 & 17.53 & 0.766 & 4.37 & تمتللك الثركة القدرة على التكيف مع التغيرات في حجم الطلب على المنتوجات. & 3 \\
\hline 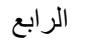 & 18.31 & 0.760 & 4.15 & تسعى الثركة إلى تقديم مجمو عة متتو عة من المنتوجات بجودة وسعر مناسبين. & 4 \\
\hline 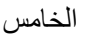 & 24.59 & 0.981 & 3.99 & تمتلك الثركة القدرة على إجر اء تغيير ات سريعة في مزيج المنتوج. & 5 \\
\hline
\end{tabular}


Amer A. K. et.al, Journal of Techniques, Vol. 3, No. 3, September 30, 2021, Pages 57-67

\begin{tabular}{|c|c|c|c|c|c|}
\hline الثاني & 16.21 & 0.697 & 4.30 & تمنلك الثركة قوى عاملة مستعدة لأداء أنواع مختلفة من مهمات الإنتاج بثكل أكثر & 6 \\
\hline$n=81$ & 19.56 & 0.816 & 4.17 & المرونة & $\mathrm{Y4}$ \\
\hline
\end{tabular}

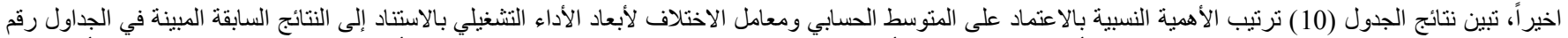

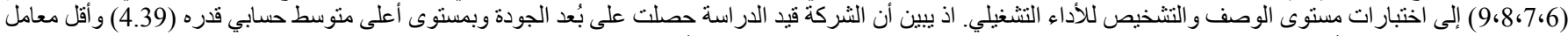

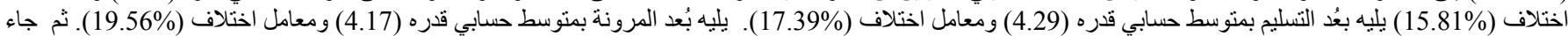
في المرتبة الاخيرة بُعد الكلفة بمتو سط حسابي قدره (4.05) و أعلى معامل اختلاف (4) (23.43\%).

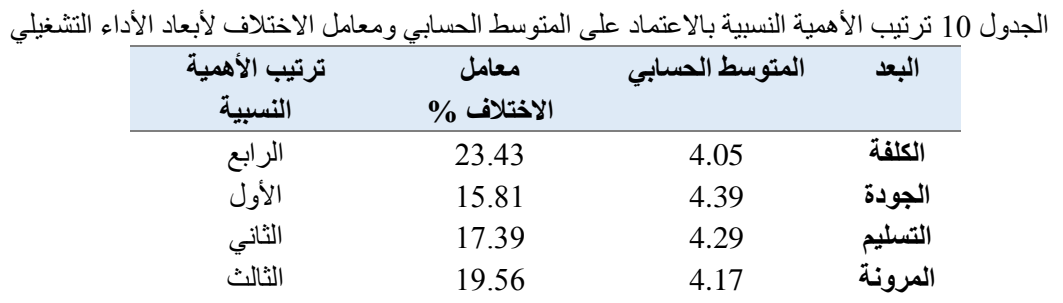

SPSS-V.24. المصدر : اعداد الباحثين باستخدام برنامج

6.4. اختبار فرضيات علاقة الارتباط والتأثير لمتغيرات البحث

تم اختبار الفرضيات الرئيسة و الفرعية المتعلقة بمعرفة علاقة الارتباطو التأثير لمتغيرات البحث (المتغير المستقل المتمثل بالصيانة الذاتبة والمتغير التابع المتمثل بالاداء التشغيلي). 6.4.1. اختبار فرضيات علاقة الارتباط بين متغيرات البحث يوضح الجدول (11) ملخصا لنتائج معامل الارتباط إلى متغير ات در اسة البحث.

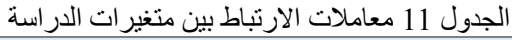

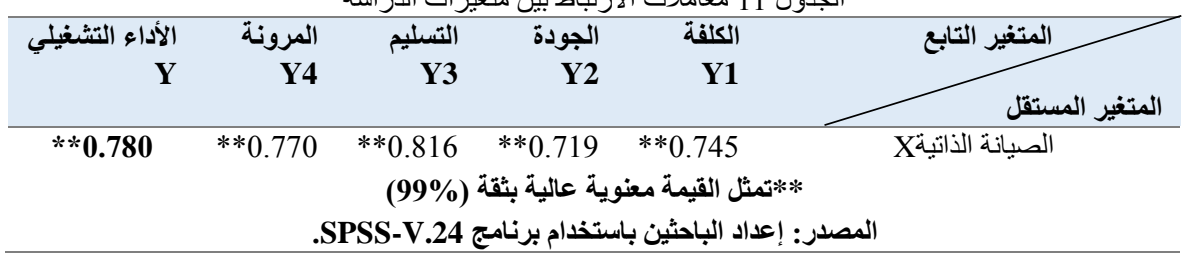

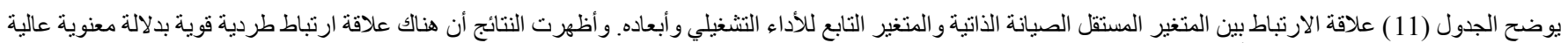

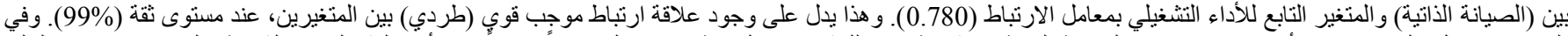

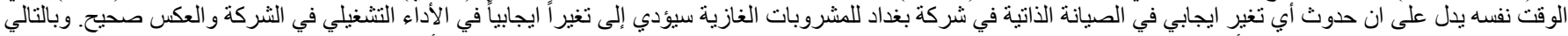

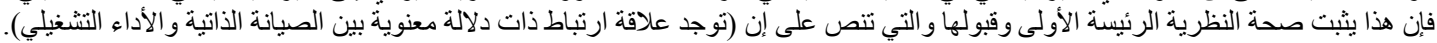

6.4.2. اختبار فرضيات نأثثر المتغير المستقل (الصيانة الذاتية) في المتغير التابع (الأداء التشغيلي):

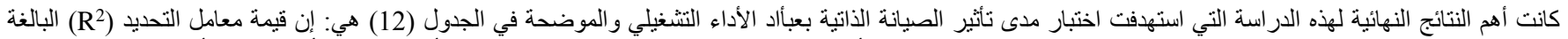

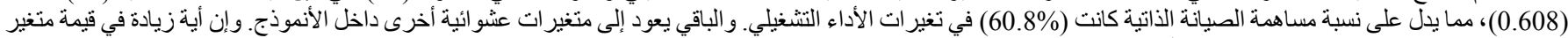

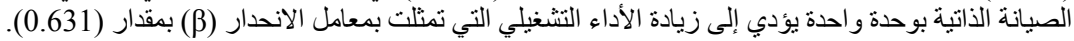

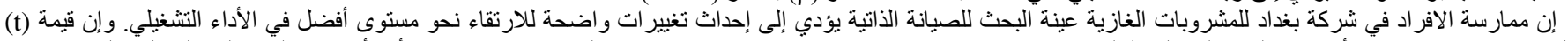

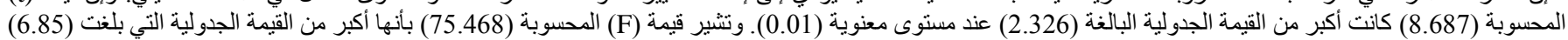

عند مستوى معنوية (0.01) بمستوى ثنة (99\%)

\begin{tabular}{|c|c|c|c|c|c|c|c|c|}
\hline طبيعة العلاقة & $\begin{array}{c}\text { مستوى الدلالة } \\
\text { P }\end{array}$ & قيمة F المحسوبة & قالمحسوبة & $\begin{array}{c}\text { الحد الثابت } \\
\alpha\end{array}$ & $\begin{array}{c}\text { معامل الاتحدار } \\
\text { P (التأثير) }\end{array}$ & $\begin{array}{c}\text { التحديد } \\
\text { معامل } \\
\mathbf{R}^{2}\end{array}$ & 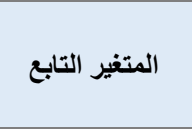 & المستغير \\
\hline معنوية عالية & 0.000 & $* * 34.353$ & $* * 5.861$ & 0.994 & 0.727 & 0.555 & Y1الكلفة Y1 & \\
\hline معنوية عالية & 0.000 & $* * 29.246$ & $* * 5.408$ & 2.539 & 0.440 & 0.517 & 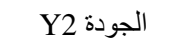 & \\
\hline معنوية عالية & 0.000 & $* * 53.125$ & $* * 7.289$ & 1.407 & 0.689 & 0.666 & 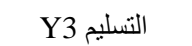 & \\
\hline معنوية عالية & 0.000 & $* * 40.261$ & $* * 6.345$ & 1.373 & 0.666 & 0.593 & 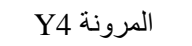 & 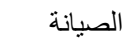 \\
\hline 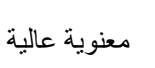 & 0.000 & $* * 75.468$ & $* * 8.687$ & 1.578 & 0.631 & 0.608 & 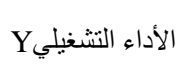 & 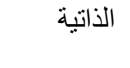 \\
\hline \multicolumn{8}{|c|}{ صحة الفرضية الفرعية الثانية بمعنوية عالية عند مستوى ثقة 99\% } & علاقة التأثير \\
\hline \multicolumn{9}{|c|}{ (99\%) } \\
\hline \multicolumn{9}{|c|}{ المصدر: إعداد الباحثين باستخدام برنامج SPSS-V.24. } \\
\hline
\end{tabular}


في ضوء نتائج تحليل البيانات ناقش البحث الحالي النقاط الآتية:

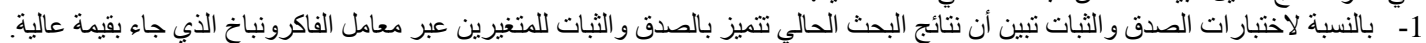

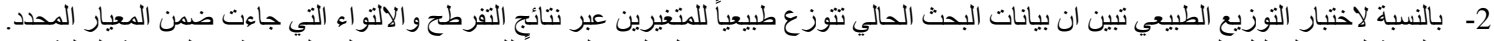

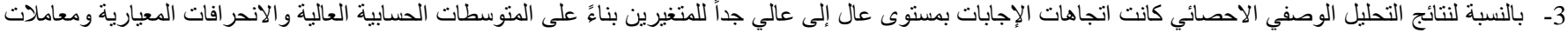
الاختلاف القليلة.

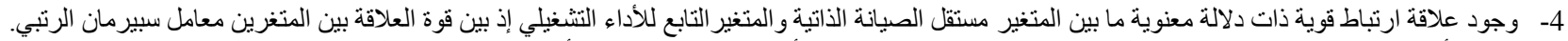

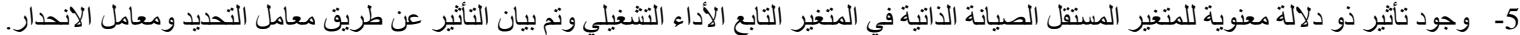

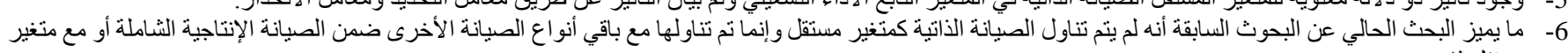
مستقل ثان.

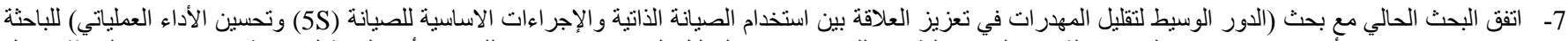

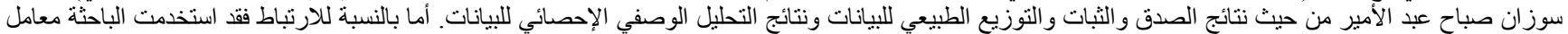

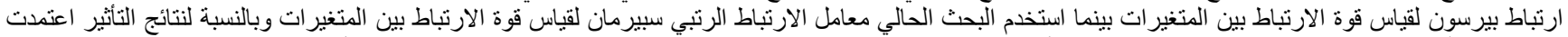

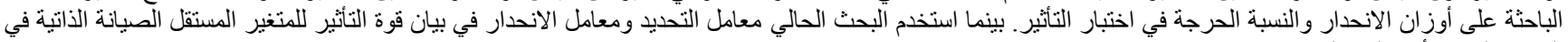
المتغير التابع الأداء التشغيلي.

7.

توصلت هذه الدراسة إلى استنتاجات وتوصيات متعددة ومن أهمها الآتي:

7.1. الاستنتاجات

1- أثارت نتائج تحليل الارتباط إلى وجود علاقة ارتباط طردية قوية بدلالة معنوية ما بين الصيانة الذاتية والأداء التشغيلي، وهذا يعني قبول الفرضية الرئيسة الأولى، نستنتج من ذلك

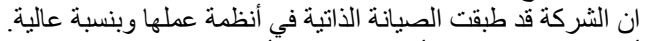

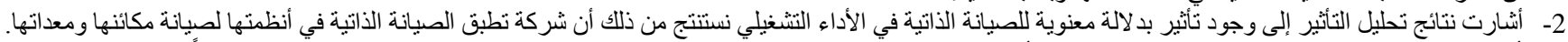

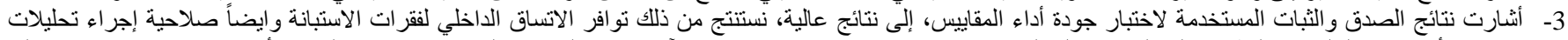

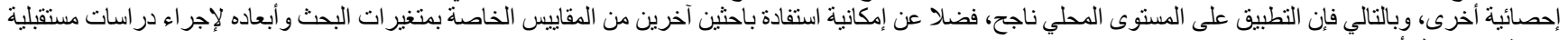
في قطاعات عمل أخرى. 4- أشَارت نتائج التوزيع ان البيانات و أبعاد متغير ات الدر اسة الحالية كانت موزعة بشكل طبيعي.

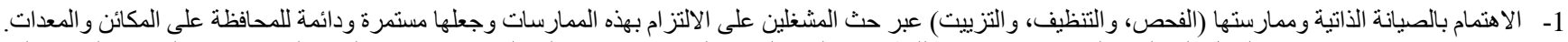

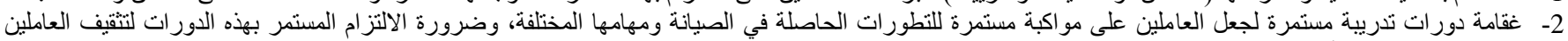

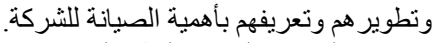

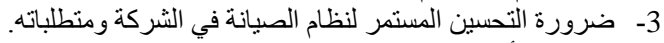

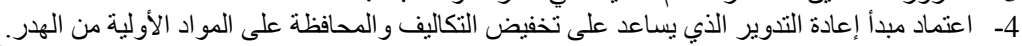

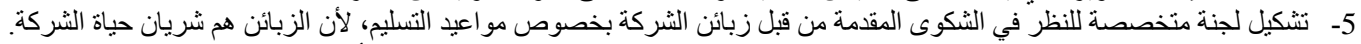

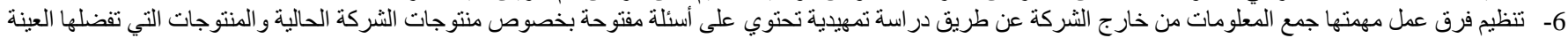

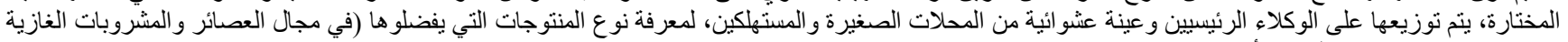

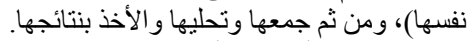

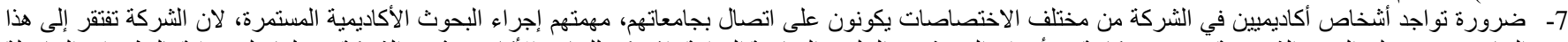

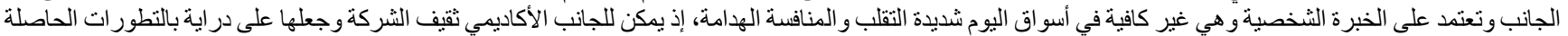
في مجالات إنتاجها.

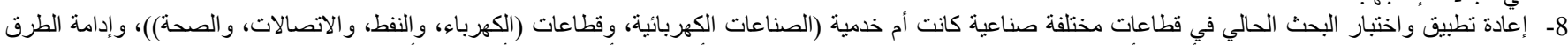

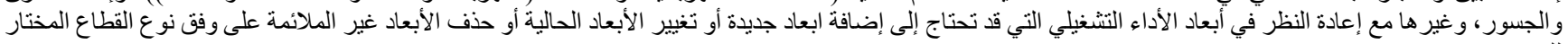

\section{8.}

بناءً على تحليل بيانات البحث ومناقثة النتائج تم اقتر اح الأنموذج الاحصائي الذي بإمكانه إفادة الباحثين من التعرف على النتائج التي توصل إليها البحث الحالي ومقارنتها بنتائجهم

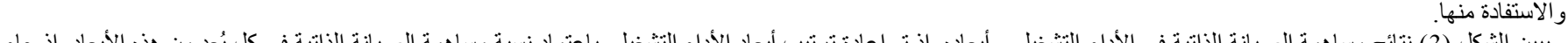

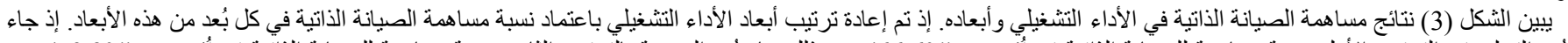

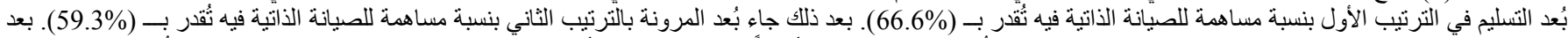

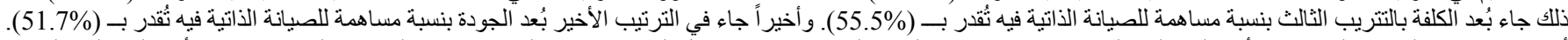

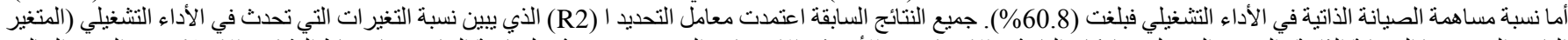

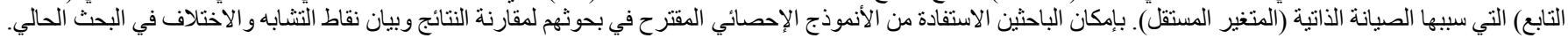




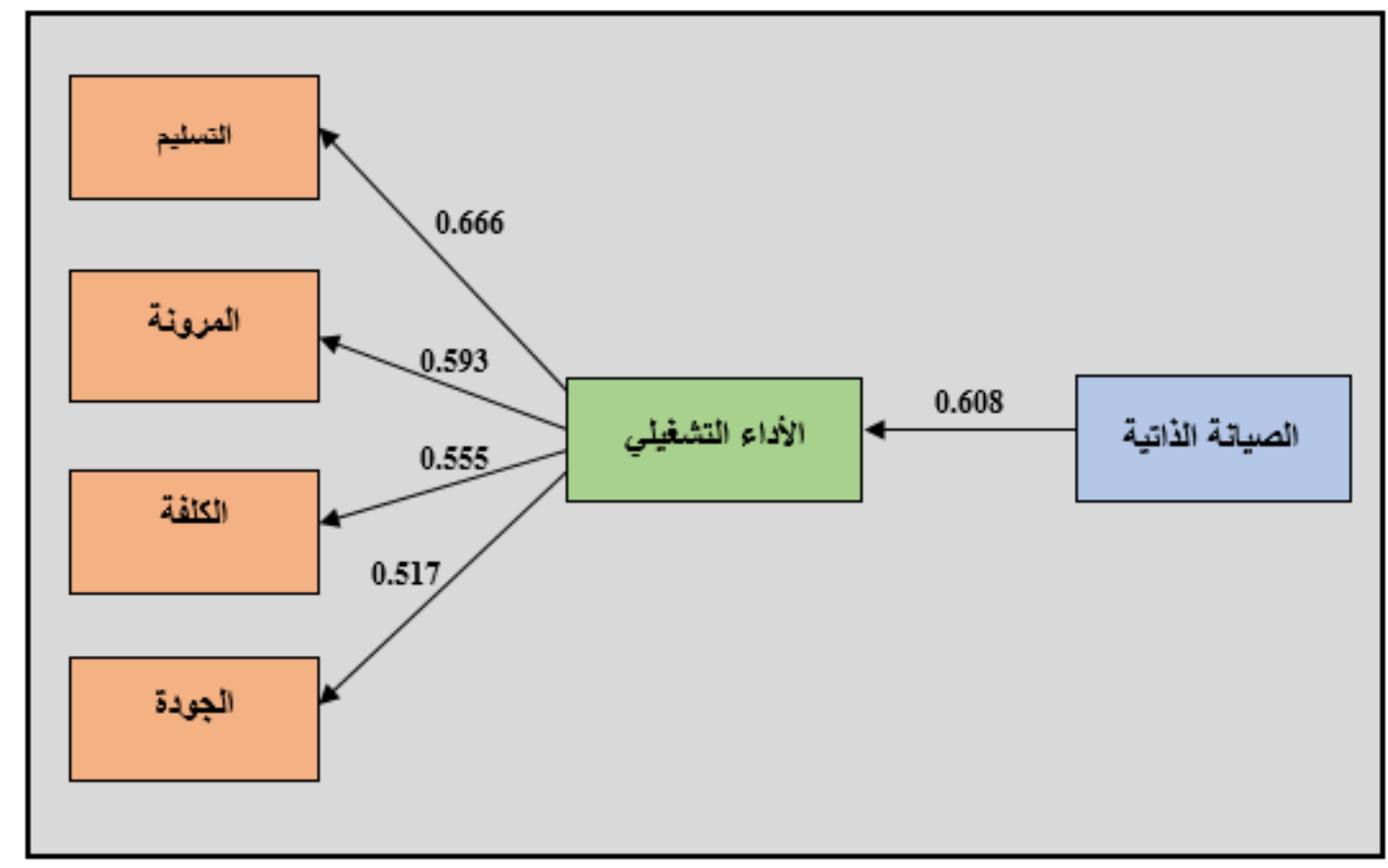

الثكل (3) الانموذج الاحصائي المقترح

المصدر: إعداد الباحثين بالاعتماد على نتائج برنامج SPSS-V.24.

\section{Reference}

[1] Al-Mindlawi, Mustafa Salah Gumer," The Effect of Entrepreneurial Competencies in Operations Performance: An Exploratory Study in Middle Refineries Company (Dora Refinery)”, M.A. dissertation, Dept. Operations Management Techniques, Middle Technical University, Baghdad, 2018.

[2] Baluch, Nazim, Abdullah, Che Sobry \& Mohtar, Shahimi. (2012, June). "TPM \& Lean Maintenance- A critical review”. Interdisciplinary Journal of Contemporary Research in Business. Vol. 4, No. 2, PP: 850-857.

[3] Khalfan, Issa, Said, Sulaiman, Jamaluddin, Zaharuzaman \& Widyarto, Setyawan. (2020, April). "Conceptual Framework on Quality Management Practices and Operational Performance for ISO 9001 Certified Construction Industries". International Journal of Academic Research in Accounting, Finance and Management Sciences, Vol. 10, No. 2, PP: 200-210.

[4] Musman, Ahmadi Hamdan \& Ahmad, Rosmaini. (2018). "Critical component identification and autonomous maintenance activities determination using fuzzy analytical hierarchy process method”. International Journal of Industrial and Systems Engineering, Vol. 28, No. 3, PP: 360-378.

[5] Hidayat, Dindin \& Suhendar, Endang. (2020, September). "Penerapan Autonomous Maintenance Dalam Mengurangi Technical Stopages Departemen Can Making Di Pt. Frisian Flag Indonesia Plant Ciracas”. Vol. 1, No. 2, PP: 82-88. https://doi.org/10.36418/jist.v1i2.22.

[6] Filho, Aglei Duques Maciel, Silva, Jonas Gomes da \& Lima, Mariana Sarmanho de Oliveira. (2019, December). "Impact of Autonomous Maintenance on a PIM Production Line”. International Journal for Innovation Education and Research. Vol. 7, No. 12, PP: $385-398$. Available: https://doi.org/10.31686/ijier.vol7.iss12.2084.

[7] Agustiady, Tina Kanti \& Cudney, Elizabeth A., Total Productive Maintenance: Strategies and Implementation Guide, 1st ed. Taylor \& Francis Group, 2016.

[8] Azizi, Amir. (2015, October). "Evaluation Improvement of Production Productivity Performance using Statistical Process Control, Overall Equipment Efficiency, and Autonomous Maintenance”. Procedia Manufacturing. Vol. 2, PP: 186-190.

[9] Kirui, Elson K. \& Maina, Kimani E. (2018, October). "effect of optimization practices on operational performance of construction industry in uasin gishu county, kenya". International Academic Journal of Economics and Finance, Vol. 3, Issue 2, PP: 309-322.

[10] Russell, Roberta S. \& Taylor, Bernard W., Operations Management: Creating Value Along the Supply Chain, 7th ed., John Wiley and Sons, 2011.

[11] Usman, Indrianawati, Hartani, Nira Hariyatie \& Sroka, Mariusz. (2020, June). "Operational Performance of the SMA: The impact of Entrepreneurial Leadership, Good Governance and Business Process Management”. Polish Journal of Management Studies. Vol. 21, No. 1, PP: 408-418.

[12] Chakravorty, Tulika, Jha, Karunakar \& Barthwal, Sunil. (2019, June). "Linking EHR and ERP Adoption with Flexibility in Care-Delivery and Operational Performance: A Conceptual Review in Hospital Supply Chain”. Indian Journal of Public Health Research \& Development. Vol. 10, No. 6, PP: 102-108.

[13] Hamad, Ahmed Abdulqader, Tuzlukaya, Şule \& Kırkbeşoğlu, Erdem. (2019, June). "The Effect of Social Capital On Operational Performance: Research in Banking Sector in Erbil”. Copernican Journal of Finance \& Accounting. Vol. 8, Issue 1, PP: 103-124. 
[14] Sadq, Zana Majed, Mohammed, Hazhar Omer, Othman, Bestoon \& Saeed, VianSulaiman Hama. (2020, January). “Attitudes of Managers in the Knowledge Private University towards the impact of Human Capital in Achieving Competitive Advantages". Test Engineering and Management, Vol. 82, PP: 393 - 401.

[15] Tomioka, Aparecida Massako \& Neves, José Manoel Souza das. (2020, March). "Key performance indicators to improve the competitive dimensions of the construction company". Research, Society and Development, Vol. 9, No. 5, PP: 1-25. http://dx.doi.org/10.33448/rsdv9i5.3130.

[16] Abdullah, Yakaw Hamad, Agala, Salih Rasul \& Abdulkarim, Peshkawt Abdullah. (2020, April). "The Role of Social Responsibility Accounting on Achieving Competitive Advantages (An Empirical Study from Perspectives of a Number of Employees in Accounting and Financial Departments in a Number of Private Universities in Iraqi Kurdistan Region)" .International Journal of Multicultural and Multireligious Understanding. Vol. 7, Issue 3, PP: 212-235.

[17] Ghanem, Fathallah A. (2018, April). "Cost of Quality as A Tool to Improve The Palestinian Industrial Organization Competitive Advantage". International Journal of Business Quantitative Economics and Applied Management Research. Vol. 4, Issue 11, PP: 35-53.

[18] Mohammed, Widad Mousa, Weli, Ameera Shukur \& Ismael, Firas Mohammed. (2019, May). "Application of Electronic Commerce and Competitive Advantage: A Case Study of Electrical Appliances Trading Companies in Baghdad". Journal of Engineering and Applied Sciences, Vol. 14, No. 9, PP: 3040-3052.

[19] Alomian, Nayef Rage, Alsawalhah, Ayyoub Ahmad \& Almarshad, Mohammad Nasser. (2019, April). "The Impact of Strategic Intelligence on Achieving Competitive Advantage: Applied Study on the Pharmaceutical Companies Sector in Jordan”. International Journal of Business and Social Science. Vol. 10, No. 4, PP: 66-74.

[20] Slack, Nigel, Chambers, Stuart \& Johnston, Robert, Operations Management, 6th ed., Pearson Education Limited, 2010.

[21] Swink, Morgan \& Melnyk, Steven A. \& Hartley, Janet L., Managing Operations: Across the Supply Chain, 4th ed., McGraw-Hill Education, 2020.

[22] Sachitra, Vilani. (2017, January). "Review of Competitive Advantage Measurements: Reference on Agribusiness Sector". Journal of Scientific Research \& Reports, Vol. 12, No. 6, PP: 1-11.

[23] Massoudi, Aram Hanna. (2018, August). “Achieving Competitive Advantage by Using Supply Chain Strategies”, International Journal of Supply Chain Management, Vol. 7, No. 4, PP: 22-29.

[24] Jacobs, F. Robert \& Chase, Richard B., Operations and Supply Chain Management, 15th ed., McGraw-Hill Education, 2018.

[25] Slack, Nigel, Jones, Alistair Brandon \& Johnston, Robert, Operations Management, 7th ed., Pearson Education Limited, 2013.

[26] Krajewski, Judie \& Malhotra, Maya \& Ritzman, Barbara, Operations Management: Processes and Supply Chains, 11th ed., (Global Edition), Pearson Education Limited, 2016.

[27] AL-Amri, Ahmad Mohammed. (2018, April). "Strategic Management Accounting and the Dimensions of Competitive Advantage: Testing the Associations in Saudi Industrial Sector". International Journal of Academic Research in Accounting, Finance and Management Sciences. Vol. 8, No. 2, PP: 48-64.

[28] Abker, Adam Yagoub, Mohammed, Mustafa Adam, Adam, Alamin Mohammed \& Mohamed, Anwar Tebein. (2018, Dec.). "Investigation the Relationship between technological capabilitiesand operational performance in the Sudanese service firms". Journal of Total Quality Management. Vol. 19, No. 2, PP: 17-30.

[29] Khorsheed, Rebaz Khaleel, Abdulla, Daroon F., Othman, Bestoon Abdulmaged, Mohammed, Hazhar Omer \& Sadq, Zana Majed. (2020, May). "The Role of Services Marketing Mix 7P's on Achieving Competitive Advantages (The Case of Paitaxt Technical Institute in Kurdistan Region of Iraq)". Test Engineering and Management, Vol. 83, PP: 15947- 15971.

[30] Slack, Nigel, Chambers, Stuart \& Johnston, Robert, Operations Management, 5th ed., Pearson Education Limited, 2007.

[31] Şengül, M., Alpkan, L. \& Eren, E. (2015, June). "Effect of Globalization on the Operational Performance: A Survey on SMEs in the Turkish Electric Industry”, International Business Research, Vol. 8, No.7, PP: 57-67.

[32] Jr., Joseph F. Hair, Black, William C., Babin, Barry J. \& Anderson, Rolph E., Multivariate Data Analysis, 7th ed., Pearson Education Limited, 2014.

[33] Likert, R., Atechique for the Measurement of Attitudes, Columbia University press., 1932. 